\title{
The effect of motivational states on ECS-induced perseveration*
}

\author{
JOSEPH B. KEYES and GEORGE L. DEMPSEY \\ Louisiana State University, Baton Rouge, Louisiana 70803
}

\begin{abstract}
Forty-eight naive male albino rats were given 6 days of acquisition training in a straight runway. Following training on the first 5 days of acquisition, all Ss received $10 \mathrm{~g}$ of Lab Chow approximately $10 \mathrm{~min}$ after the experimental session. Upon completion of acquisition, Ss received either ECS or no treatment and were given 0, 10 , or $20 \mathrm{~g}$ of food. All Ss were tested in extinction $24 \mathrm{~h}$ after treatment, and results showed that as motivational level decreased, the running speed of no-treatment Ss declined at a greater rate than did the running speed of Ss receiving ECS. This was interpreted in terms of the perseveration effect of ECS on the runway response.
\end{abstract}

The most widely accepted explanation of the effect of electroconvulsive shock (ECS) has been the hypothesis of memory consolidation (McGaugh, 1966). This theory postulates that after learning, memory is in the form of a trace which must undergo some type of neural consolidation to become fixed or permanent. During this fixation period, the memory trace is susceptible to disruption, and if ECS is administered, permanent memory loss will result.

Recently, however, a number of alternative explanations for the effect of ECS have been suggested (Spevack \& Suboski, 1969). Adams, Peacock, and Hamrick (1967), for example, have suggested that ECS acts as disinhibitor. Still another alternative explanation has been put forth by Chorover and Schiller (1966), who suggest that the effects of ECS at long postlearning intervals are on the conditioned emotional response instead of memory.

In a more recent study, Young and Galluscio (1970) trained two groups of rats to leverpress on either a continuous reinforcement schedule (CRF) or a fixed-ratio schedule (FR3). Following acquisition, all Ss were allowed to make one leverpress on treatment day. For half the Ss in each group, a leverpress produced footshock; for the other half, a leverpress produced footshock which was immediately followed by ECS. All Ss were then tested on a 10-min extinction session $24 \mathrm{~h}$ later. As expected, results showed that for both schedules of reinforcement, Ss given ECS responded significantly more in extinction than did Ss receiving shock only.

A critical finding of this study, however, was the failure of FR-trained animals to show the partial reinforcement effect (PRE) in extinction. In fact. CRF-trained Ss receiving ECS made more responses during extinction than did FR-trained Ss given ECS.

Replicating the Young and Galluscio study, Young and Day (1971) employed a variable-ratio schedule (VR) of reinforcement in place of the FR schedule used in the

\footnotetext{
*This research was supported in part by a grant from the Graduate Research Council, Louisiana State University, to A. G. Young.
}

previous study. Results indicated that the VR(ECS) group failed to show the PRE when compared with the CR(ECS) group. The VR(ECS) group did make more responses during extinction than the CR(ECS) group, but the difference was small and not statistically significant. This finding was in agreement with those of Young and Galluscio (1970).

The authors hypothesized that the combined findings suggested that the effect of ECS is not the disruption of a memory trace resulting in retrograde amnesia (RA), but rather the effect may be an inflated rate of responding or a perseveration of responding in extinction. They further suggested that since this effect would be more noticeable for CRF-trained Ss, which typically cease responding far sooner than Ss trained on a partial reinforcement schedule (PR), the result would be a reduction in the difference between the CRF and PR groups and thus a loss of the PRE.

The present study was therefore designed to evaluate the perseverating effect of ECS on the runway response, and to determine how it is affected by level of motivation.

\section{METHOD}

Subjects

The Ss were 48 naive male albino rats, $175-200 \mathrm{~g}$ in weight at the start of the experiment.

\section{Apparatus}

The apparatus consisted of a Plexiglas straight runway, $45 \frac{1}{2}$ in. long, 4 in. wide, and 4 in. high. The startbox, which was $7 \mathrm{in.} \mathrm{long} \mathrm{and} 4 \mathrm{in}$. wide, was separated from the runway by a guillotine door mounted in transverse plastic tracks. The goalbox was 10 in. long and 6 in. wide and was also separated from the runway by a Plexiglas guillotine door. On the far wall of the goalbox was mounted a foodcup. The entire floor of the apparatus consisted of $3 / 8$-in. bronze rods spaced $1 / 2$ in. on centers. When the startbox door was raised. a .1-sec clock was started. When the animal entered the goalbox, a photobeam was interrupted and the clock was stopped.

\section{Procedure}

The Ss were selected randomly from the LSL colony, placed 


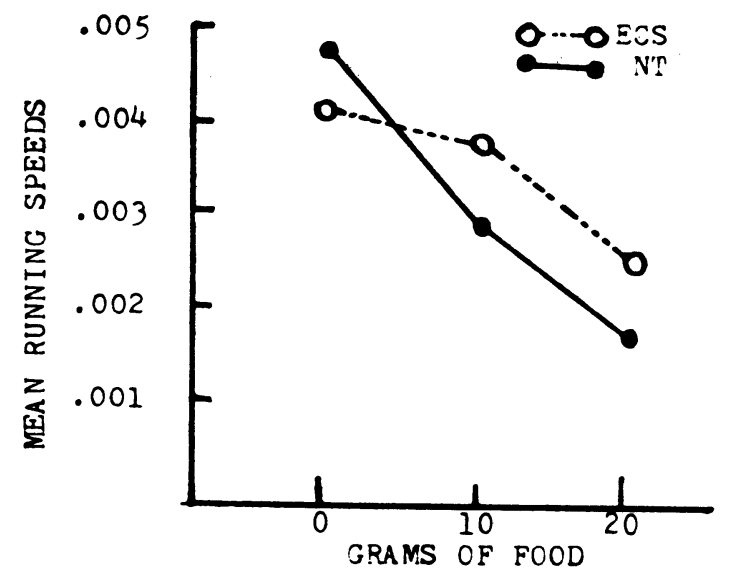

Fig. 1. Mean running speeds for no treatment (NT) and ECS groups as a function of the level of motivation.

in individual cages, and kept on a food-deprivation schedule of $10 \mathrm{~g}$ Purina Chow every $24 \mathrm{~h}$. Water was available at all times, and $\mathrm{Ss}$ were fed approximately $10 \mathrm{~min}$ after each experimental session. Following a 4-day adaptation period to the deprivation schedule, Ss were handled in pairs for $5 \mathrm{~min}$ daily for 4 days. After the last day of handling, Ss were given $10 \mathrm{~g}$ of Noyes standard food pellets. On Days 9 and 10, the animals explored the alley in groups of two for 10 and $2 \mathrm{~min}$, respectively, with the photobeams operative, all doors open, and no food in the goalbox. After each day of exploration, all $\mathrm{Ss}$ were given five direct, reinforced placements in the goalbox. On Day 11, acquisition began. Each animal received 5 rewarded trials on the first day of acquisition and 10 rewarded trials on each of the next 5 days. There was thus a total of 55 trials. All Ss were run on a continuous reinforcement schedule, using one 45-mg Noyes pellet as reward. There was a 20 -sec intertrial interval.

After completion of acquisition training, the $\mathrm{Ss}$ were subdivided randomly, resulting in the following six groups (eight Ss per group): $\operatorname{ECS}(0), \operatorname{ECS}(10), \operatorname{ECS}(20)$, NT(0), NT(10). NR(20). Immediately following the last acquisition trial. Ss in Groups $\operatorname{ECS}(0)$. ECS $(10)$, and $\operatorname{ECS}(20)$ were removed from the apparatus. placed in a carrying cage, and taken to an adjacent room where they were fitted with microalligator earclips and administered a 50-mA $500-\mathrm{msec}$ ECS. They were then taken back to their home cages and given either 0,10 , or $20 \mathrm{~g}$ of food. For the Ss in Groups NT(0), NT(10), and NT(20), the procedure was identical. except that no ECS treatment (NT) was administered.

Behavioral observations indicated that all Ss were mobile and began to consume their food within $1 / 2 h$ of treatment. All Ss consumed the total amount of food given them.

Twenty-four hours after treatment, all Ss were given 30 extinction trials. During extinction, the stimulus conditions were the same as during acquisition, except that reinforcement was withheld.

\section{RESULTS}

The response latencies during extinction were recorded at the end of 10 trials and also following 20 and 30 trials. All latencies were converted to speed scores $(1 / \mathrm{sec})$.

The results for the first 10 trials showed that the NT(0) group ran the fastest, followed in order by Groups ECS $(0), \operatorname{ECS}(10), \quad$ NT(10), ECS $(20)$, and NT(20). These data were subjected to an analysis of variance, which showed that the effect of level of motivation was significant beyond the .01 level.

The results for the first 20 trials indicated that the fastest running times were made by Group NT( 0$)$. followed in order by Groups ECS(0). ECS(10). NT(10). ECS(20), and NT(20). These data were subjected to an analysis of variance which showed that the effect of level of motivation was significant beyond the .01 level.

The results of the complete 30 trials showed that the NT(0) group ran the fastest. followed in order by Groups ECS $(0)$, ECS(10). NT(10). ECS(20), and NT(20). These data were subjected to an analysis of variance which showed that the effect of level of motivation was significant beyond the .ô level and that the Treatment by Level of Motivation interaction was significant beyond the .05 level. Figure 1 shows the mean running speeds of the no-treatment and ECS groups as a function of the level of motivation.

A priori group comparisons ( $t$ tests) showed that the comparison NT(0) vs NT(10) was significant beyond the .01 level, with the comparisons NT(10) vs NT(20) and $\operatorname{ECS}(10)$ vs $\operatorname{ECS}(20)$ significant beyond the .05 level. The comparisons NT(0) vs ECS(0), NT(20) vs ECS(20), and $\operatorname{ECS}(0)$ vs $\operatorname{ECS}(10)$ were not significant at the .05 level.

The significant interaction (Fig. 1) indicates that as the level of motivation decreased, the running speed of no-treatment Ss declined at a greater rate than the running speed of Ss given ECS.

An analysis of the response latencies for the last day of acquisition indicated that there were no differences between the NT and ECS groups or among the 0-, 10-, or 20-g groups (Mann-Whitney U).

\section{DISCUSSION}

The most critical finding of this study was the finding that the Treatment by Level of Motivation interaction was significant. Under the highest level of motivation $(0 \mathrm{~g})$, Ss in both treatment groups responded at a high rate. As level of motivation was decreased to $10 \mathrm{~g}$, however, the running speed of no-treatment animals decreased significantly. There was no difference, however, between the running speeds of Groups $\operatorname{ECS}(0)$ and ECS(10). When the level of motivation was reduced still further $(20 \mathrm{~g})$, the running speeds for both the ECS and NT groups declined significantly.

These results support the ECS perseveration effect explanation of Young and Day (1971). This perseveration effect seems to appear only under moderate levels of motivation. Together, these studies suggest that ECS inflates the rate of responding or perseverates responding in extinction.

Regardless of the interpretation of these results, the present study indicates that the effects of ECS are dependent in part upon the level of motivation. 


\section{REFERENCES}

Adams, H. E.. Peacock, L. J., \& Hamrick, D. D. ECS and one-trial learning: Retrograde amnesia or disinhibition? Physiology \& Behavior, 1967, 2, 435-437.

Chorover, S. L., \& Schiller, P. H. Short-term retrograde amnesia in rats. Journal of Comparative \& Physiological Psychology, 1965, 59, 73-78.

McGaugh, J. L. Time-dependent processes in memory storage. Science, 1966, 153, 1351-1358.

Spevack, A. A., \& Suboski, M. D. Retrograde effects of electroconvulsive shock on learned responses. Psychological Bulletin. 1969, 72, 66-76.

Young. A. G., \& Day, H. D. Effect of ECS on one-trial learning and on the partial reinforcement effect. Psychonomic Science, 1971, 24, 99-100.

Young, A. G., \& Gallascio, E. H. Effect of ECS on one-trial learning following continuous and partial reinforcement training. Psychonomic Science, 1970, 21, 43-44.

(Received for publication August 28, 1972; revision received October 30,1972 .) 